\title{
A New STATCOM Based on T Type Three Level Inverter
}

\author{
Zhi Xu${ }^{1}$, Shengnan $\mathrm{Li}^{1 *}$, Risheng Qin ${ }^{1}$, Wensen Yan $^{2}$ and Yanhang Zhao ${ }^{2 *}$ \\ ${ }^{1}$ Electric Power Research Institute, Yunnan Electric Power \\ Company, Kunming, China \\ xuzhi1123@163.com,lsn788@sina.com*,514927517@qq.com \\ ${ }^{2}$ State Key Laboratory of Power Transmission Equipment \& System Security and \\ New Technology, Chongqing University, Chongqing, China \\ yanwensen123@163.com,zhaoyanhang@cqu.edu.cn
}

\begin{abstract}
A new type of static synchronous compensator (STATCOM) based on $T$ three level inverter is proposed. Compared with the traditional three level STATCOM, the new STATCOM based T three level inverter has the advantages of less required devices, less switching loss and uniform loss distribution. Differences of the two three-level inverters in terms of efficiency and loss are compared. Working principle of three-level T type inverter D-STATCOM is analyzed in detail, and hysteresis control is applied to achieve reactive power compensation under three patterns of fixed reactive power compensation, dynamic switching and sudden load change. According to the simulation result, compared with three-level neutral point clamped inverter D-STATCOM, three-level $T$ type D-STATCOM is characterized by advantages of simple structure, low cost, less loss, which can well fit the future development tendency of power grid.
\end{abstract}

Keywords: Neutral point clamped, three-level T type inverter, D-STATCOM, low loss

\section{Introduction}

Reactive compensation and harmonic suppression have been the focus of research on power system. As a reactive compensation approach, STATCOM has attracted the unceasing and extensive attention of academic field and industrial circle due to its good dynamic response, low harmonic distortion rate, small volume and low cost $[1,2]$.

STATCOM based on cascaded $\mathrm{H}$ bridge inverter is one of the research focuses in reactive power compensation field. The total output voltage is obtained by superimposing the output voltages of the plurality of $\mathrm{H}$ bridge modules. The cascaded $\mathrm{H}$ bridge multilevel topology adopts modular design, which has the advantages of easy redundancy, high expansibility, easy replacement and high reliability. Therefore, cascaded $\mathrm{H}$ bridge multilevel topology is often preferred in high voltage and high power STATCOM devices[3].

For STATCOM with small or medium capacity, predominance of traditional two-level inverters is being gradually replaced by multi-level inverters $[4,5]$. Compared with the traditional two level inverter, the three level inverter has the following characteristics: First, the switching off voltage of each thyristor is only half of that of the DC bus voltage, so it is suitable for high voltage and large capacity applications; Second, it can generate five levels of line voltage. Thus, in the same switching frequency and control mode, the harmonic content of the output voltage and current is much smaller than the traditional two level inverter. Especially, the neutral point clamp (NPC) type three level inverter[6]. In contrast with traditional two-level inverter, NCP structure is obviously remarkable in terms of withstand voltage pressure of switch tube, waveform deviation factor, voltage

Received (November 22, 2016), Review Result (July 10, 2017), Accepted (August 23, 2017) 
change ratio and device loss [7-9]. But it has inconsistent phenomena of anti-parallel diode loss and different switching loss of switch tube to cause unbalanced device heat. Besides, NCP has problems of large quantity in device number and much loss, which bring safety risk to the system[10].

Therefore, taking advantages of less device quantity and loss for three-level $\mathrm{T}$ type inverter, energy-saving D-STATCOM based on three-level T type inverter is proposed in this paper. Compared with the traditional three level STATCOM, the new STATCOM based $\mathrm{T}$ three level inverter has the advantages of less required devices, less switching loss and uniform loss distribution.

\section{NPC and Three-level T Type Inverter}

A cascaded $\mathrm{H}$ bridge inverter can be used to generate a five level. This topology is widely used today. A cascaded $\mathrm{H}$ bridge inverter can be used to generate a five level. This topology is widely used today. However, with the development of multilevel inverters, the defects of loss and waveform distortion are gradually exposed by the cascade of two level inverters. Therefore, this paper mainly analyzes and compares the NPC and T three level inverters.

\subsection{Topological Structure Analysis}

Each phase of three-level NPC topology has four fully-controlled switch devices and two clamping diodes. DC voltage source consists of two capacitors in series with voltage value of $V_{d c}$. The maximum voltage for each switch is $V_{d c} / 2$, see Figure 1 .

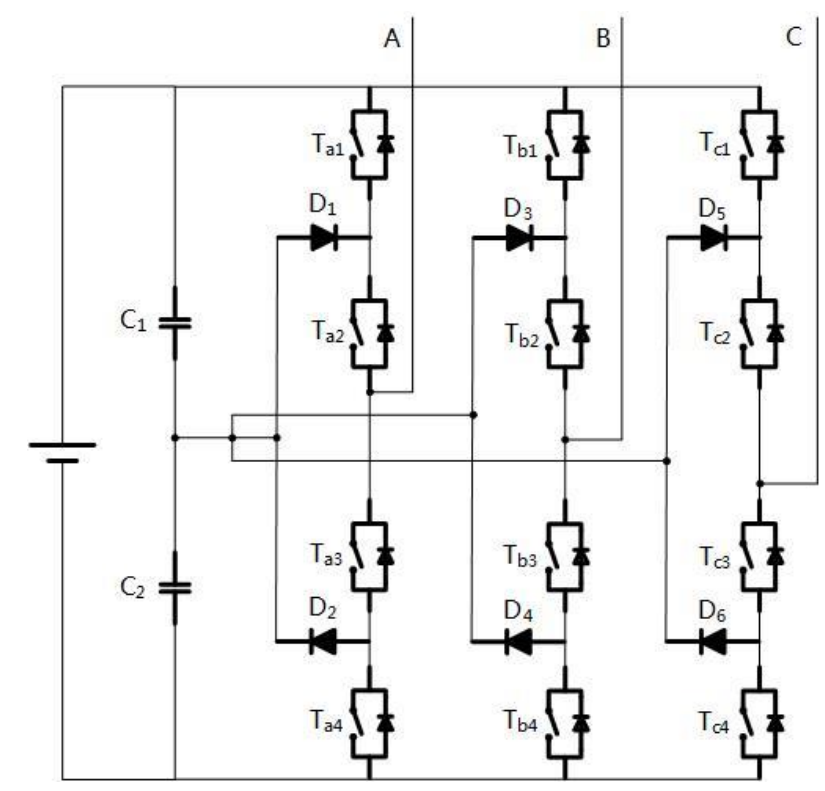

Figure 1. Traditional NPC Topology

Each phase of NPC topology has three kinds of output states: $+1,0$ and -1 . Taking A phase as example, turn on $\mathrm{T}_{\mathrm{a} 1}$ and $\mathrm{T}_{\mathrm{a} 2}$ meanwhile turn off $\mathrm{T}_{\mathrm{a} 3}$ and $\mathrm{T}_{\mathrm{a} 4}$ to output +1 , turn on $\mathrm{T}_{\mathrm{a} 2}$ and $\mathrm{T}_{\mathrm{a} 3}$, turn off $\mathrm{T}_{\mathrm{a} 1}$ and $\mathrm{T}_{\mathrm{a} 4}$ to output 0 , turn on $\mathrm{T}_{\mathrm{a} 3}$ and $\mathrm{T}_{\mathrm{a} 4}$, turn off $\mathrm{T}_{\mathrm{a} 1}$ and $\mathrm{T}_{\mathrm{a} 2}$ to output -1 . So NPC on-off state is shown as Table 1, in which $\mathrm{k}=\mathrm{a}, \mathrm{b}, \mathrm{c}$. According to the analysis above, $T_{a 1}$ is only on when output is +1 . $T_{a 4}$ is only on when output is -1 . $T_{a 2}$ is on when output is +1 and $0 . T_{\mathrm{a} 3}$ is on when the output is 0 and -1 [11, 12]. Break-over and turn-off time of the four switching tubes are not at the same time, thus the switching loss of switching tube and anti-parallel diode current flow loss are distributed in a unbalanced way. 


\section{Table 1. NPC Structure Switch Status Table}

\begin{tabular}{|c|c|c|c|c|}
\hline $\mathrm{T}_{\mathrm{k} 1}$ & $\mathrm{~T}_{\mathrm{k} 2}$ & $\mathrm{~T}_{\mathrm{k} 3}$ & $\mathrm{~T}_{\mathrm{k} 4}$ & output \\
\hline 1 & 1 & 0 & 0 & +1 \\
\hline 0 & 1 & 1 & 0 & 0 \\
\hline 0 & 0 & 1 & 1 & -1 \\
\hline
\end{tabular}

NPC structure is optimized and improved to obtain three-level T type structure, see Figure 2. Compared with NPC, T type topology is a half-bridge structure with only one switching tube on both bridge arms, and two clamping diodes are reduced. Two-way switching tube with reverse connection is used to achieve neutral point voltage clamp, see $\mathrm{T}_{\mathrm{a} 2}$ and $\mathrm{T}_{\mathrm{a} 3}$ in Figure $2[13]$.

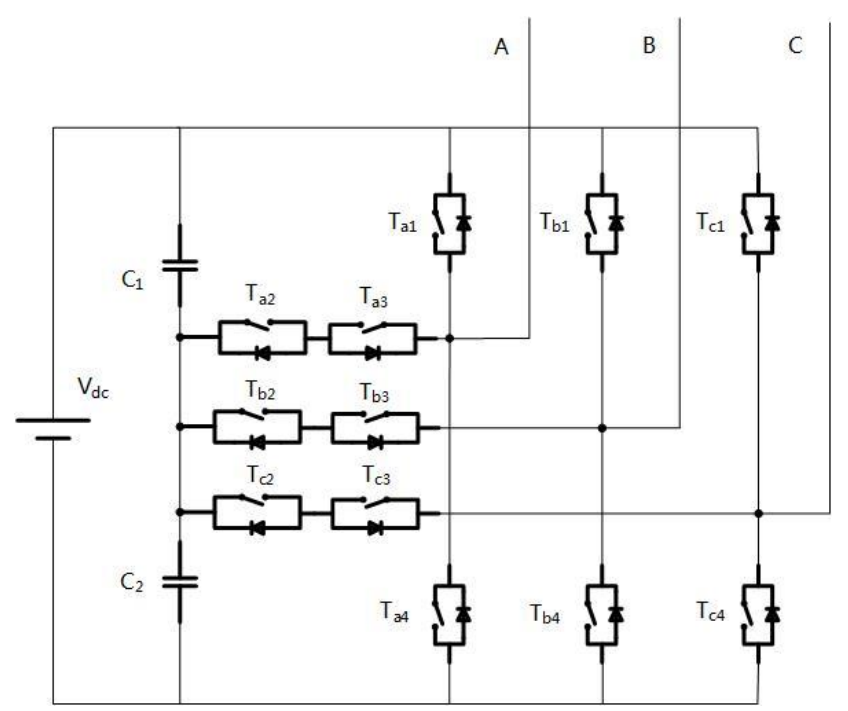

Figure 2. T Type Topological Structure

The same modulation strategy is applied for three-level T type and NPC inverter. The on-off state is seen in Table 1 . When the load current is positive, circulating path of $\mathrm{T}$ type topology under three kinds of on-off states can be seen in Figure 3. When $T_{a 1}$ and $T_{a 2}$ are on and $\mathrm{T}_{\mathrm{a} 3}$ and $\mathrm{T}_{\mathrm{a} 4}$ are off, output is +1 , see Figure 3(a). At this time, $\mathrm{T}_{\mathrm{a} 2}$ is on but no current. When $\mathrm{T}_{\mathrm{a} 2}$ and $\mathrm{T}_{\mathrm{a} 3}$ are on and $\mathrm{T}_{\mathrm{a} 1}$ and $\mathrm{T}_{\mathrm{a} 4}$ are off, output is 0 , see Figure 3(b). When $\mathrm{T}_{\mathrm{a} 3}$ and $\mathrm{T}_{\mathrm{a} 4}$ are on and $\mathrm{T}_{\mathrm{a} 1}$ and $\mathrm{T}_{\mathrm{a} 2}$ are off, output is -1, see Figure 3(c). At this time, $\mathrm{T}_{\mathrm{a} 3}$ is on but no current. 


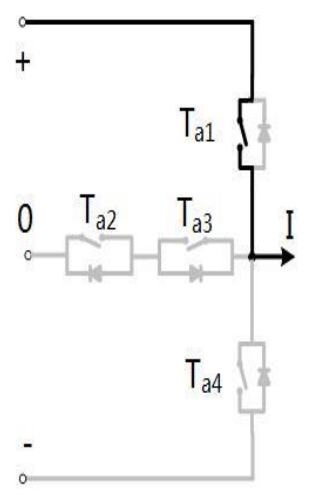

(a)

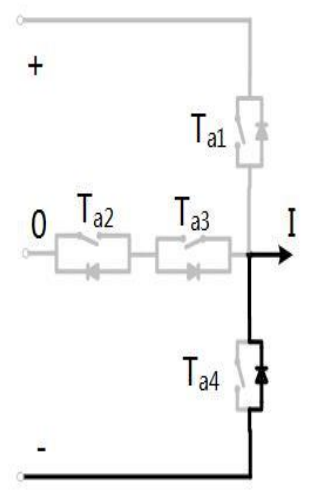

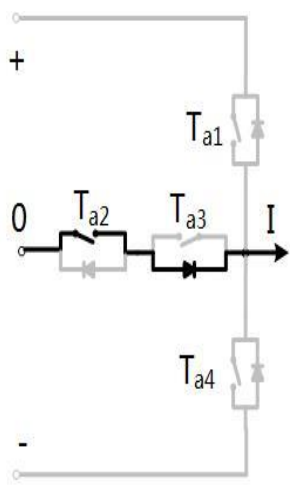

(b)

(c)

\section{Figure 3. Current Path of T Type Three Level Inverter}

When output is +1 or -1 , two NPC switching tubes on both bridge arms have breakover loss, while for three-level $\mathrm{T}$ type topology. There is only one switching tube with conduction loss. When output is 0, one NPC switching tube and one clamping diode have breakover loss, and for T type, two two-way clamping switching tubes have breakover loss.

\subsection{Simulation Analysis for Loss of Two Topological Structures}

The differences of the two topologies are compared in detail from four aspects, such as IGBT loss, backward parallel diode loss, switching loss, and clamping diode loss. It can be seen that the $\mathrm{T}$ type topology is less expensive, It can be seen that the $\mathrm{T}$ type topology is less expensive, and working with T topology helps to improve work efficiency[14].

To verify the correctness of aforementioned theory, three-level NPC and T type simulation models are built in Matlab. The same parameters are used for both experimental models. The input direct voltage is $600 \mathrm{~V}$ and output alternating voltage frequency is $50 \mathrm{~Hz}$. Load power is $20 \mathrm{~kW}$, and simulation time is $0.25 \mathrm{~s}$. First, simulation is done to three-level NPC topology structure to work out its working efficiency as $97.95 \%$, then, simulation is done to $\mathrm{T}$ type inverter to figure out its working efficiency as $98.50 \%$. On this basis, inverter input power can be changed by changing the value of DC voltage source. Table 2 shows the comparison of working efficiency of the two topological structures under different input power. 


\section{Table 2. Efficiency Comparison of Two Topologies under Different Input} Power

\begin{tabular}{|c|c|c|}
\hline $\begin{array}{l}\text { External } \\
\text { input power } \\
/ \mathrm{kW}\end{array}$ & $\begin{array}{l}\text { Efficiency } \\
\text { of T type } \\
\text { topology } / \%\end{array}$ & $\begin{array}{l}\text { Efficiency of } \\
\text { NPC topology } \\
\text { /\% }\end{array}$ \\
\hline 20 & 99.73 & 99.19 \\
\hline 18 & 99.71 & 99.1 \\
\hline 16 & 99.67 & 98.86 \\
\hline 14 & 99.61 & 98.6 \\
\hline 12 & 99.51 & 98.25 \\
\hline 10 & 99.36 & 97.77 \\
\hline 8 & 99.15 & 97.13 \\
\hline 6 & 98.82 & 96.07 \\
\hline 4 & 98.3 & 94 \\
\hline 2 & 96.78 & 89.38 \\
\hline
\end{tabular}

According to the simulation result, the trend chart for efficiency of the two topological structures when changing input power can be depicted as Figure 4.

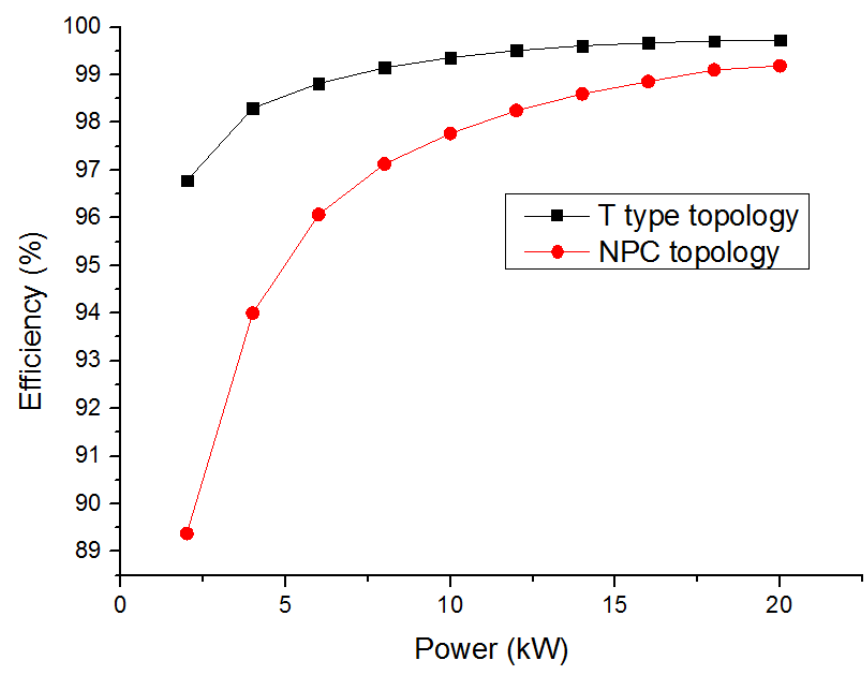

Figure 4. The Efficiency Trend of the Two Kinds of Topology Structure

From Figure 4, the efficiency of the two structures is improved as input power grows, and the efficiency of T type topology is apparently higher than that of NPC structure. So compared with NPC topology, T type topology inverter has advantages of low loss and high efficiency.

\section{Three-Level T Type D-STATCOM}

Apply three-level T type inverter in STATCOM as Figure 5. Three-phase four-wire system is adopted for connection. When there is reactive element in load, the grid needs to offer not only active element but also reactive element. The system power factor angle is not 0 . At this time, STATCOM needs to be connected to provide all reactive power to ensure that only active power is released by the grid, meanwhile, its voltage and current are in the same direction. The power factor angle is 0 .

Connecting with STATCOM, relations of the grid current, load current and compensating current are as follows: 


$$
i_{s k}+i_{f k}=i_{l k}
$$

Where $\mathrm{k}=\mathrm{a}, \mathrm{b}, \mathrm{c}, i_{s \mathrm{k}}$ representing grid current, $i_{f k}$ representing compensation current and $i_{l k}$ representing load current.

\subsection{Reference Current}

D-STATCOM compensating accuracy is determined by the precision of compensating current command signal, and the time for its signal acquirement affects the dynamic response speed of D-STATCOM. The method of obtaining compensating currents can be simply divided into the following three:

In the abc coordinate system, the grid current can be obtained through the grid voltage and power factor. Reference current $i_{f a}^{*}, i_{f b}^{*}, i_{f c}^{*}$ can be figured out by difference of load current and grid current. See Formula (2) for its calculation. In the formula, $V_{\mathrm{sa}}, \mathrm{V}_{\mathrm{sb}}$ and $\mathrm{V}_{\mathrm{sc}}$ is grid voltage, $\gamma=\tan \varnothing / \sqrt{3}$. $\varnothing$ is power factor angle. $P_{\text {lavg }}$ is average load active power. $P_{\text {loss }}$ is D-STATCOM loss, $\Delta=\sum_{k=a, b, c} V_{s k}^{2}[15]$.

$$
\left\{\begin{array}{l}
i_{f a}^{*}=i_{l a}-\frac{v_{s a}+\gamma\left(v_{s b}-v_{s c}\right)}{\Delta}\left(P_{\text {lavg }}+P_{\text {loss }}\right) \\
i_{f b}^{*}=i_{l b}-\frac{v_{s b}+\gamma\left(v_{s c}-v_{s a}\right)}{\Delta}\left(P_{\text {lavg }}+P_{\text {loss }}\right) \\
i_{f c}^{*}=i_{l c}-\frac{v_{s c}+\gamma\left(v_{s a}-v_{s b}\right)}{\Delta}\left(P_{\text {lavg }}+P_{\text {loss }}\right)
\end{array}\right.
$$

In the $\alpha \beta$ coordinate system, reference current is obtained via reversely reasoning the formula of active and reactive power, then, matrix transformation is used to gain reference current under abc coordinate system. See Formula (3) for reference current calculation. $i_{f \alpha}{ }^{*}, i_{f \beta}{ }^{*}$ is compensating current command signal under $\alpha \beta$ coordinate system. $V_{\alpha}, V_{\beta}$ is grid voltage under $\alpha \beta$ coordinate system. $\widetilde{P}$ is alternating current of transient active power. $Q$ is transient reactive power[16].

$$
\left[\begin{array}{l}
i_{f \alpha}^{*} \\
i_{f \beta}^{*}
\end{array}\right]=\frac{1}{V_{\alpha}^{2}+V_{\beta}^{2}}\left[\begin{array}{cc}
V_{\alpha} & V_{\beta} \\
V_{\beta} & -V_{\alpha}
\end{array}\right]\left[\begin{array}{l}
-\tilde{P} \\
-Q
\end{array}\right]
$$

The load current under abc coordinate system is converted to active and reactive current under $d q 0$ coordinate system by means of transient reactive power theory, and reactive current is taken as reference current[17].

In this paper, directive current $i_{f k}{ }^{*}$ is substituted by $i_{s k}{ }^{*}$. The amplitude of the reference current $i_{s k}{ }^{*}$ can be obtained by the capacitor neutral-point potential with the PI control. The phase of the $i_{s k}{ }^{*}$ can be obtained by the grid voltage with the PLL. The structure of three-level T type D-STATCOM controller is shown in Figure 5.

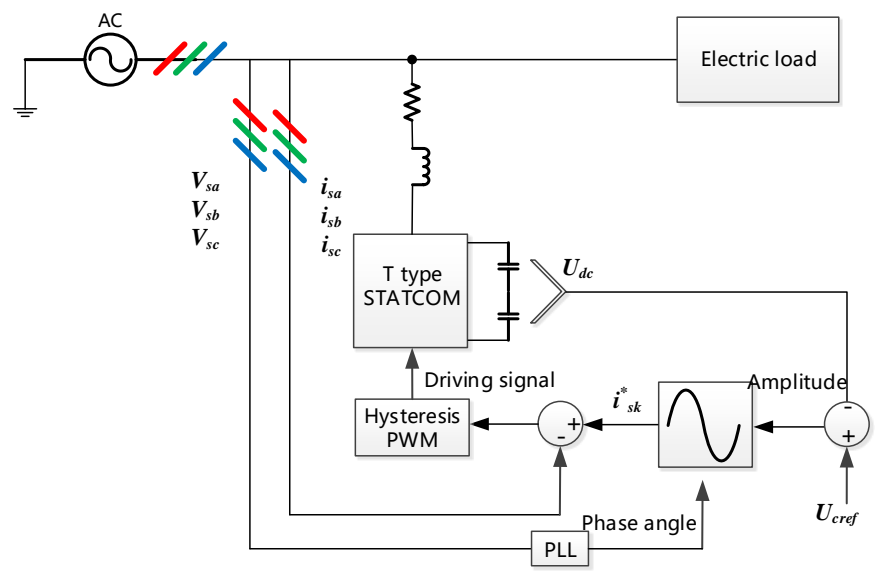

Figure 5. STATCOM Control Structure 


\subsection{PWM of Hysteresis Control}

The compensating current command signal is passed into the hysteresis comparator to generate a drive signal for controlling the switching of the switching tube, so that the $\mathrm{T}$ type three level STATCOM generates an appropriate compensation current. Three-level hysteresis comparator is used to generate driving signals for all switching tubes, see Formula (4). In the formula, $H_{k 1}$ and $H_{k 2}$ are the output of upper and lower hysteresis comparators on phase $k$, separately.

$$
\left\{\begin{array}{l}
T_{k 11}=\overline{T_{k 3}}=H_{k 1} \\
T_{k 44}=\overline{T_{k 2}}=H_{k 22}
\end{array}\right.
$$

\subsection{Simulation and Analysis}

Simulation models of three-level NPC and $\mathrm{T}$ type STATCOM are built in Matlab/simulink. Circuit parameters for the two models are set the same. The grid line voltage is $380 \mathrm{~V}$. The frequency is $50 \mathrm{~Hz}$ and DC side capacitance is $5 \mathrm{mF}$. The reference value of capacitor voltage is $600 \mathrm{~V}$, and $\mathrm{AC}$ filter inductance is $2 \mathrm{mH}$. Figure 6 is the schematic diagram of the main circuit of the STATCOM simulation model based on the T three level inverter. The STATCOM based on the T three level inverter is connected in parallel with the reactor in the power grid. By controlling the switching on of the switch tube, the STATCOM can compensate the power grid with proper reactive power. The logic of the triggered signal is shown in Figure 5. The following are some simulation results obtained on the simulation platform.

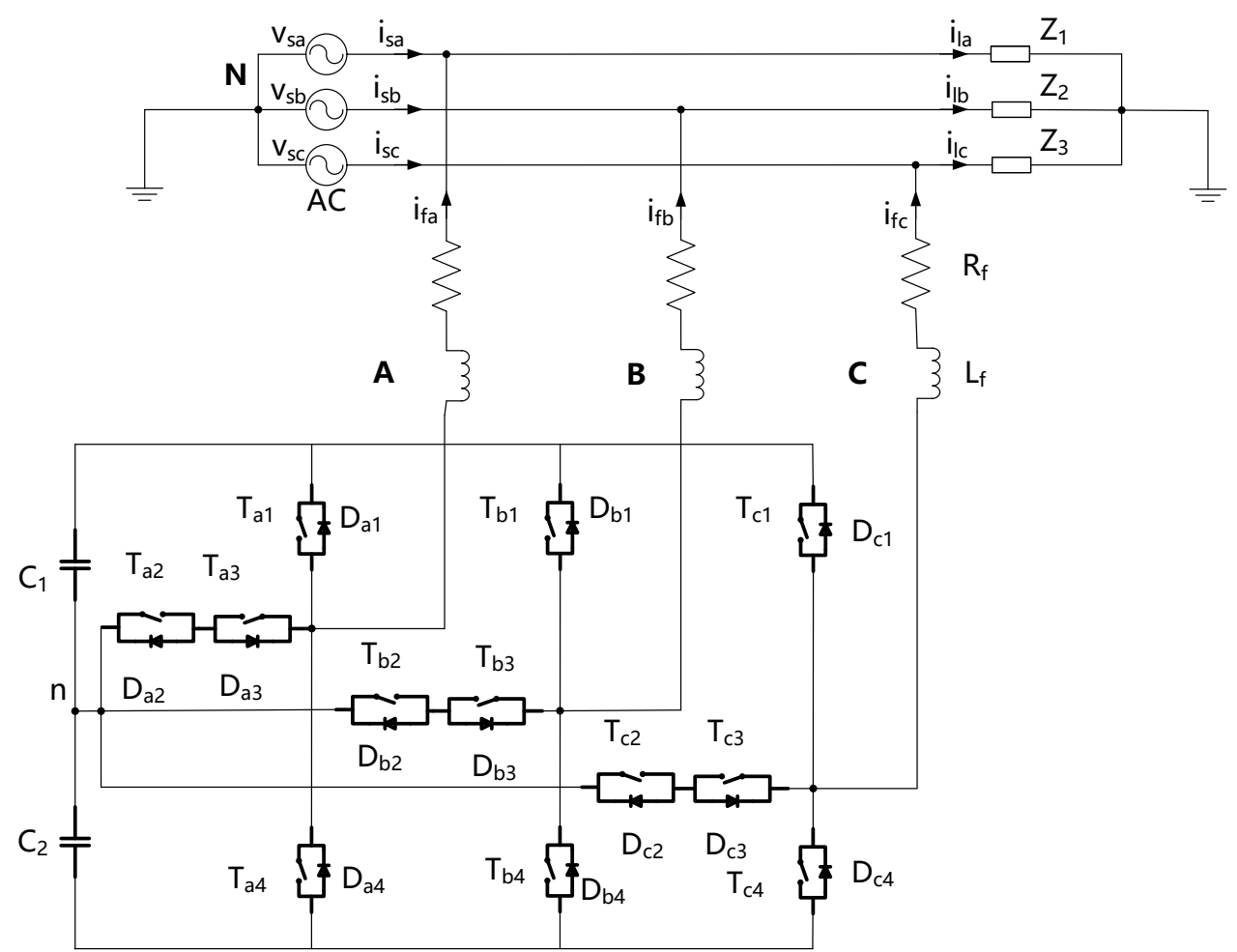

Figure 6. Schematic Diagram of the Main Circuit Simulation

Fixed reactive compensation mode: load $\mathrm{P}=15 \mathrm{~kW}, \mathrm{Q}=10 \mathrm{kvar}$, input STATCOM when $\mathrm{t}=0.25 \mathrm{~s}$. Set reactive compensation value as $5 \mathrm{kvar}$. Before connection with STATCOM, power factor is 0.667 , which means grid current lags grid voltage $33.69^{\circ}$. After connection with STATCOM, the system active power is not changed. The reactive power 
is changed from 10kvar to $5 \mathrm{kvar}$ and the power factor is 0.333 , which means grid current lags grid voltage $18.43^{\circ}$. Current waveform and system power waveform under fixed reactive compensation mode are shown in Figure 7 and Figure 8.

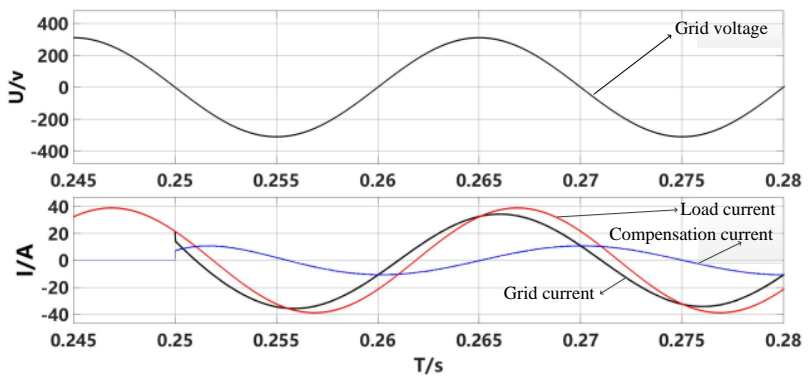

Figure 7. Power Grid Voltage, Grid Current, Load Current and Compensation Current Waveform

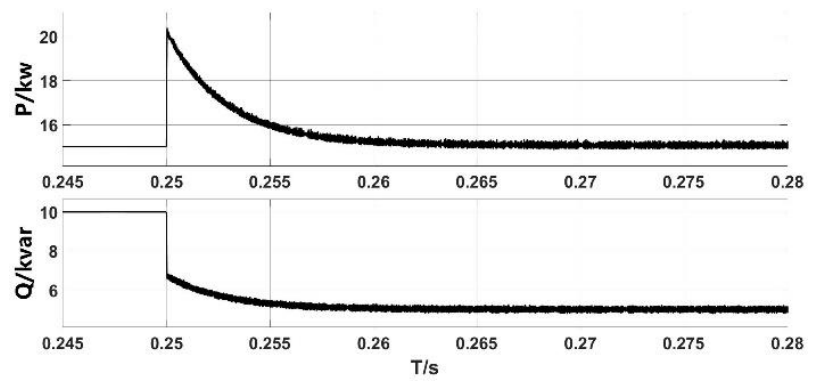

Figure 8. Reactive Power and Reactive Power Waveform

From Figure 7 and Figure 8, before connection with STATCOM, $i_{s a}=i_{l a}$. Both lag grid voltage $33.69^{\circ}$ in the same direction and pull ahead after $0.25 \mathrm{~s}$, lagged grid voltage angle is changed from $33.69^{\circ}$ to $18.43^{\circ}$. And Figure 7 shows active and reactive change of the system after input STATCOM. STATCOM reaches steady state after $0.255 \mathrm{~s}$. The reactive compensation value is $5 \mathrm{~kW}$, the same as theoretical value.

Dynamic switching mode: load $\mathrm{P}=15 \mathrm{~kW}, \mathrm{Q}=10 \mathrm{kvar}$, connect with STATCOM when $\mathrm{t}=0.25 \mathrm{~s}$ and disconnect it when $\mathrm{t}=0.3 \mathrm{~s}$. The theoretical value of STATCOM for reactive compensation is 0 before $0.25 \mathrm{~s}$. $10 \mathrm{~kW}$ within $0.25-0.3 \mathrm{~s}$ and 0 again after $0.3 \mathrm{~s}$, which means grid current lags grid voltage $33.69^{\circ}$ and it is in the same direction with grid voltage within $0.25-0.3 \mathrm{~s}$. After $0.3 \mathrm{~s}$, it lags $33.69^{\circ}$. Current waveform and system power waveform under dynamic switching mode are shown in Figure 9 and Figure 10.

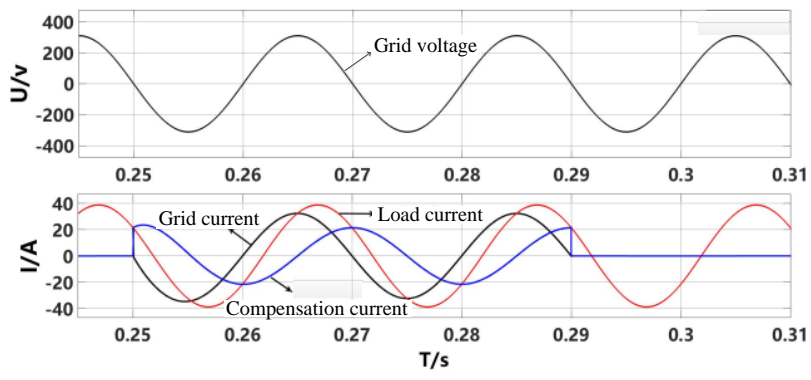

Figure 9. Power Grid Voltage, Grid Current, Load Current and Compensation Current Waveform 


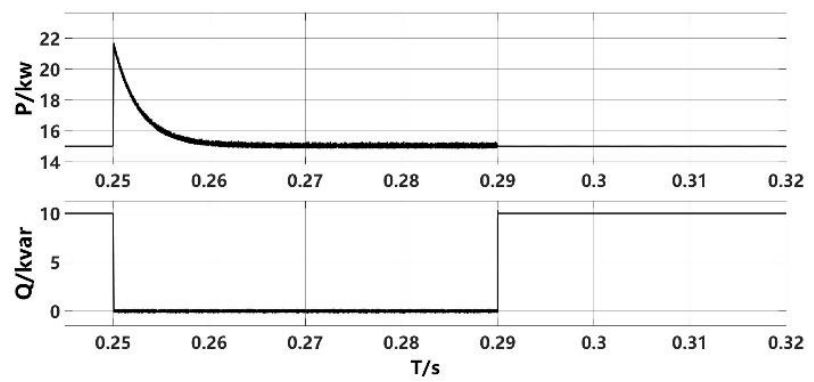

Figure 10. Active and Reactive Waveforms in Dynamic Switching

From Figure 9 and Figure 10, grid current and grid voltage are in the same direction when input STATCOM. The system reactive power is compensated completely by STATCOM. When disconnected with STATCOM, grid current and load current are in the same direction. The reactive power is released fully by STATCOM.

Sudden load change mode: load $\mathrm{P}=15 \mathrm{~kW}, \mathrm{Q}=10 \mathrm{kvar}$, connect with $\mathrm{STATCOM}$ when $\mathrm{t}=0.25 \mathrm{~s}$. Change load as $\mathrm{P}=20 \mathrm{~kW}, \mathrm{Q}=18 \mathrm{kvar}$ when $\mathrm{t}=0.35 \mathrm{~s}$. Theoretical value for reactive compensation of STATCOM changes from 0 to $10 \mathrm{~kW}$, and then to $18 \mathrm{~kW}$. Current waveform and system power waveform under sudden load change mode are shown in Figure 11 and Figure 12.

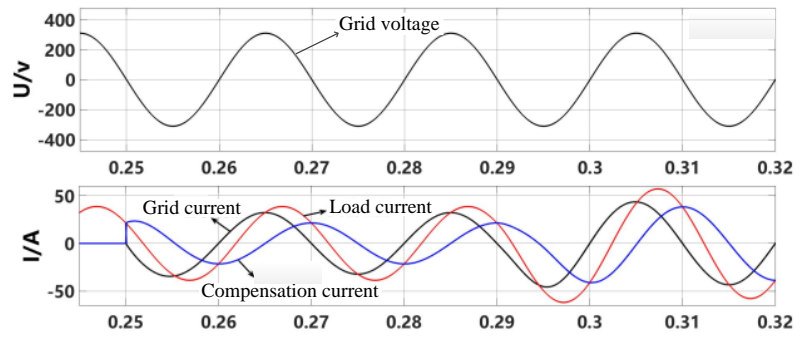

Figure 11. Load Jump Time Grid Voltage, Grid Current, Load Current and Compensation Current Waveform
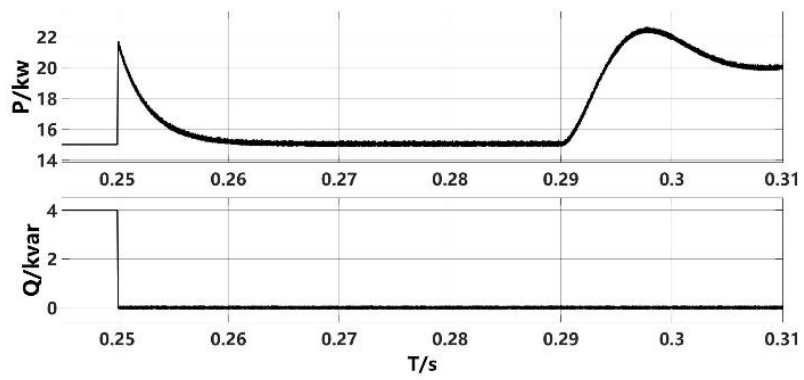

Figure 12. Active and Reactive Waveforms in Load Jump

From Figure 11 and Figure 12, after connection with STATCOM, grid current and grid voltage are always in the same direction in spite of change in load. The active power released by grid changes with load, while the reactive power keeps 0 always, which means the reactive power is compensated completely by the three-level $T$ type STATCOM.

From Figure 12, when the system is connected with three-level T type STACOM, it can well meet the requirement of load reactive compensation with fast dynamic response speed and high precision under fixed reactive compensation, dynamic switching and sudden load change. 
Besides, build a STATCOM simulation model with NPC as main circuit. The circuit parameters are set the same as three-level T type STATCOM. Their active power is compared under different loads as Table 3. It can be seen from Table 3, three-level T type and NPC STATCOM can meet the requirement of load reactive compensation well. But for three-level $\mathrm{T}$ type, its consumption of active power is low and the operating cost is low as well.

Table 3. NPC and T Type Three Level Distortion and Loss

\begin{tabular}{|c|c|c|c|c|c|}
\hline \multicolumn{2}{|c|}{ Load } & \multicolumn{2}{c|}{ NPC-STATCOM } & \multicolumn{2}{c|}{ T type-STATCOM } \\
\hline $\mathrm{P} / \mathrm{kW}$ & $\mathrm{Q} /$ Kvar & THD $/ \%$ & 1 oss $/ \mathrm{w}$ & THD/\% & 1 oss $/ \mathrm{w}$ \\
\hline 2 & 2 & 3.39 & 550 & 3.39 & 130 \\
\hline 6 & 6 & 1.07 & 560 & 1.14 & 130 \\
\hline 10 & 10 & 0.66 & 580 & 0.69 & 135 \\
\hline 14 & 14 & 0.48 & 590 & 0.49 & 140 \\
\hline 18 & 18 & 0.37 & 595 & 0.38 & 145 \\
\hline 22 & 22 & 0.31 & 600 & 0.32 & 150 \\
\hline 26 & 26 & 0.27 & 600 & 0.27 & 155 \\
\hline 30 & 30 & 0.24 & 590 & 0.24 & 160 \\
\hline
\end{tabular}

\section{Conclusion}

A STATCOM based on three level T inverter is proposed. Compared with three-level NPC STATCOM, three-level T type STATCOM has fewer devices, less working loss and lower operating cost. It has fast response speed and high precision under hysteresis control. The simulation of fixed reactive power compensation, dynamic switching and load sudden change is carried out. Simulation results show that the STATCOM based on the $\mathrm{T}$ three level inverter can well meet the demand of reactive power compensation in power system. It has some practical value in the theoretical analysis and Simulation Research of the power electronic system with similar structure.

\section{References}

[1] X. Y. An, "Control method of chain STATCOM comprehensive compensation reactive and negative sequence", Electric Engineering, no. 11, (2012), pp. 15-17.

[2] Q. Xiong, Z. Zhang, X. G. Yin, M. H. Wen, J. Liu and C. P. Wang, "Research on STATCOM technology of new type distribution transformer", Transactions of China Electrotechnical Society, no. 10, (2012), pp. 262-269.

[3] Z. Ji, Y. Sun and D. Li, "Comparative analysis for unbalance compensation of cascaded H-bridge STATCOMs between star and delta configuration”, High Voltage Engineering, vol. 41, no. 7, (2015), pp. 2435-2444.

[4] D. X. Wang, "Performance improvement of D-STATCOM and its application in power distribution system", Institutes Of Technology of Tianjin, (2016).

[5] C. Zhang, "Decentralized control and implementation of chain STATCOM system", Beijing Institute of Technology, (2016)

[6] O. Husev, C. R. Clemente and E. R. Cadaval, "Three-level three-phase quasi-Z-source neutral-point-clamped inverter with novel modulation technique for photovoltaic application", Electric Power Systems Research, vol. 130, (2016), pp. 10-21.

[7] S. Song and J. Y. Chen, "Principle and Realization of STATCOM based on thyristor", Automation of Electric Power Systems, no. 18, (2006), pp. 49-54.

[8] Z. Hao, H. Bing and K. Qu, "The efficiency analysis for three-level grid-connected photovoltaic inverters", Neutral Point Clamped, (2012), pp. 1086-1090.

[9] D. P. Duang, X. C. Jiang, C. X. Sun, Q. Song and W. Tian, "D-STATCOM mathematical modeling and system simulation for unbalanced load", High Voltage Engineering, no. 8, (2008), pp. 1704-1709.

[10] A. T. Kambiz and R. Ignace, "Power loss calculation in two different multilevel inverter models (2DM2)", Electric Power Systems Research, vol. 81, (2011), pp. 297-307.

[11] H. F. Xiao, C. Yang and S. J. Xie, "Research on common mode current suppression technology of NPC three level grid connected inverter", Proceedings of the CSEE, no. 33, (2010), pp. 23-29.

[12] Y. C. Liu, X. L. Ge and X. Y. Feng, "Comparative study of two level and three level NPC inverter single bridge fault reconstruction topology SVPWM algorithm", Proceedings of the CSEE, no. 3, (2016), pp. 775-783. 
[13] W. Du, "Research on three phase T type three level photovoltaic inverter technology", University On The Mountain of Swallows, (2015).

[14] L. Q. Yuan, Z. M. Zhao, J. Z. Liu, C. J. Li and Y. H. Li, "Design simulation and analysis of high power NPC inverter based on IGCT", Electric Power Automation Equipment, no. 1, (2004), pp. 46-49+53.

[15] A. Ghosh and A. Joshi, "A new approach to load balancing and power factor correction in power distribution system", IEEE Transactions on Power Delivery, vol. 15, no. 1, (2000), pp. 417-422.

[16] G. Sahu, K. Mahapatra and S. K. Sahu, "Design and Performance Analysis of D-STATCOM for Non-linear Load Composite Compensation", Proceedings of the International Conference on Frontiers of Intelligent Computing: Theory and Applications (FICTA) 2013. Springer International Publishing, (2014), pp. 337-344.

[17] X. Wang, J. Y. Lin, L. T. Teng, K. Wang, M. Yuan, S. Y. Wu and Z. F. Deng, "Chain STATCOM current control strategy in d-q-0 coordinate system", Proceedings of the CSEE, no. 15, (2012), pp. 48-54+15.

\section{Authors}

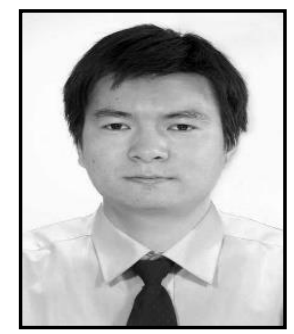

Zhi Xu, Male, postgraduate, research direction is power quality and flexible transmission. 
International Journal of Multimedia and Ubiquitous Engineering Vol.12, No.9 (2017) 